San Jose State University

SJSU ScholarWorks

Mineta Transportation Institute Publications

8-2020

\title{
Eco-Driving Systems for Connected Automated Vehicles: Multi- Objective Trajectory Optimization
}

Ke Huang

San Diego State University

Xianfeng Yang

University of Utah

Follow this and additional works at: https://scholarworks.sjsu.edu/mti_publications

Part of the Transportation Engineering Commons

\section{Recommended Citation}

Ke Huang and Xianfeng Yang. "Eco-Driving Systems for Connected Automated Vehicles: Multi-Objective Trajectory Optimization" Mineta Transportation Institute Publications (2020). https://doi.org/10.31979/ mti.2020.1924

This Report is brought to you for free and open access by SJSU ScholarWorks. It has been accepted for inclusion in Mineta Transportation Institute Publications by an authorized administrator of SJSU ScholarWorks. For more information, please contact scholarworks@sjsu.edu. 


\section{SJSU SAN JOSE START

Eco-Driving Systems for Connected Automated Vehicles: Multi-Objective Trajectory Optimization

Ke Huang, PhD

Xianfeng Yang, PhD

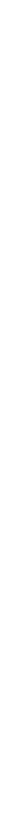




\section{MINETA TRANSPORTATION INSTITUTE}

Founded in 199I, the Mineta Transportation Institute (MTI), an organized research and training unit in partnership with the Lucas College and Graduate School of Business at San José State University (SJSU), increases mobility for all by improving the safety, efficiency, accessibility, and convenience of our nation's transportation system. Through research, education, workforce development, and technology transfer, we help create a connected world. MTI leads the four-university. MTI leads the four-university California State University Transportation Consortium funded by the State of California through Senate Bill I.

MTl's transportation policy work is centered on three primary responsibilities:

\section{Research}

MTI works to provide policy-oriented research for all levels of government and the private sector to foster the development of optimum surface transportation systems. Research areas include: bicycle and pedestrian issues; financing public and private sector transportation improvements; intermodal connectivity and integration; safety and security of transportation systems; sustainability of transportation systems; transportation / land use / environment; and transportation planning and policy development. Certified Research Associates conduct the research. Certification requires an advanced degree, generally a Ph.D., a record of academic publications, and professional references. Research projects culminate in a peer-reviewed publication, available on TransWeb, the MTI website (http://transweb.sjsu.edu).

\section{Education}

The Institute supports education programs for students seeking a career in the development and operation of surface transportation systems. MTI, through San José State University, offers an AACSBaccredited Master of Science in Transportation Management and graduate certificates in Transportation Management, Transportation Security, and High-Speed Rail Management that serve to prepare the nation's transportation managers for the 2 I st century. With the active assistance of the California Department ofTransportation (Caltrans), MTI delivers its classes over a state-of-the-art videoconference network throughout the state of California and via webcasting beyond, allowing working transportation professionals to pursue an advanced degree regardless of their location. To meet the needs of employers seeking a diverse workforce, MTl's education program promotes enrollment to under-represented groups.

\section{Information and Technology Transfer}

MTI utilizes a diverse array of dissemination methods and media to ensure research results reach those responsible for managing change. These methods include publication, seminars, workshops, websites, social media, webinars, and other technology transfer mechanisms. Additionally, MTI promotes the availability of completed research to professional organizations and journals and works to integrate the research findings into the graduate education program.MTl's extensive collection of transportation- related publications is integrated into San José State University's world-class Martin Luther King, Jr. Library.

\section{Disclaimer}

The contents of this report reflect the views of the authors, who are responsible for the facts and accuracy of the information presented herein. This document is disseminated in the interest of information exchange. The report is funded, partially or entirely, by a grant from the State of California. This report does not necessarily reflect the official views or policies of the State of California or the Mineta Transportation Institute, who assume no liability for the contents or use thereof. This report does not constitute a standard specification, design standard, or regulation. 
REPORT 20-33

\section{ECO-DRIVING SYSTEMS FOR CONNECTED AUTOMATED VEHICLES: MULTI-OBJECTIVE TRAJECTORY OPTIMIZATION}

Ke Huang, PhD

Xianfeng Yang, PhD

August 2020

A publication of

Mineta Transportation Institute

Created by Congress in 1991

College of Business

San José State University

San José, CA 95192-0219 


\section{TECHNICAL REPORT DOCUMENTATION PAGE}

1. Report No. 20-33

4. Title and Subtitle

Eco-Driving Systems for Connected Automated Vehicles: Multi-Objective Trajectory Optimization

2. Government Accession No.
3. Recipient's Catalog No.

5. Report Date

August 2020

6. Performing Organization Code

8. Performing Organization Report CA-MTI-1924

Ke Huang, PhD, https://orcid.org/0000-0002-1587-9877 Xianfeng Yang, PhD, https://orcid.org/0000-0002-9416-6882

9. Performing Organization Name and Address Mineta Transportation Institute

College of Business

San José State University

San José, CA 95192-0219

12. Sponsoring Agency Name and Address

State of California SB1 2017/2018

Trustees of the California State University

Sponsored Programs Administration

401 Golden Shore, 5th Floor

Long Beach, CA 90802

15. Supplemental Notes

DOI: 10.31979/mti.2020.1924

\section{Abstract}

This study aims to leverage advances in connected automated vehicle (CAV) technology to design an eco-driving and platooning system that can improve the fuel and operational efficiency of vehicles during freeway driving. Following a two-stage control logic, the proposed algorithm optimizes CAVs' trajectories with three objectives: travel time minimization, fuel consumption minimization, and traffic safety improvement. The first stage, designed for CAV trajectory planning, is carried out with two optimization models. The second stage, for real-time control purposes, is developed to ensure the operational safety of CAVs. Based on extensive numerical simulations, the results have confirmed the effectiveness of the proposed framework both in mitigating freeway congestion and in reducing vehicles' fuel consumption.

\section{Key Words}

Ecodriving, connected vehicles, fuel consumption, optimization, control

\section{Distribution Statement}

No restrictions. This document is available to the public through The National Technical Information Service, Springfield, VA 22161
19. Security Classif. (of this report) Unclassified
20. Security Classif. (of this page) Unclassified
21. No. of Pages

28
22. Price 


\title{
Copyright $\odot 2020$ \\ by Mineta Transportation Institute \\ All rights reserved
}

DOI: 10.31979/mti.2020.1924

\author{
Mineta Transportation Institute \\ College of Business \\ San José State University \\ San José, CA 95192-0219 \\ Tel: (408) 924-7560 \\ Fax: (408) 924-7565 \\ Email: mineta-institute@sjsu.edu
}

transweb.sjsu.edu 


\section{ACKNOWLEDGMENTS}

The authors thank Editing Press, for editorial services, as well as MTI staff, including Executive Director Karen Philbrick, PhD; Deputy Executive Director Hilary Nixon, PhD; Graphic Designer Alverina Eka Weinardy; and Executive Administrative Assistant Jill Carter. 


\section{TABLE OF CONTENTS}

Executive Summary

I. Eco-Driving Control Architecture 2

Literature Review $\quad 2$

Overview of the Proposed Framework 3

II. Optimization of CAV Trajectories at the Planning Level 6

$\begin{array}{ll}\text { Travel Time Minimization } & 6\end{array}$

$\begin{array}{ll}\text { Fuel Consumption Minimization } & 8\end{array}$

III. Real-Time CAV Trajectory Control at Operation Level 15

Speed Adaption of CAVS 15

$\begin{array}{ll}\text { CAV Platoon Operations } & 16\end{array}$

$\begin{array}{lr}\text { IV. Numerical Examples } & 17\end{array}$

CAV Trajectory Optimization Results (Planning Level) 17

Real-Time CAV Trajectory Control Results (Operation Level) 20

$\begin{array}{ll}\text { Abbreviations and Acronyms } & 22\end{array}$

$\begin{array}{ll}\text { Bibliography } & 23\end{array}$

$\begin{array}{ll}\text { About the Authors } & 27\end{array}$

$\begin{array}{ll}\text { Peer Review } & 28\end{array}$ 


\section{LIST OF FIGURES}

1. Mixed CAV and HV Driving Environment 4

2. Overview of the Two-Stage Control Framework 5

3. Freeway Segmentations $\quad 6$

4. Upstream Inflow to the Study Site 17

5. Time-Dependent Average Speed Distribution on the Most Congested Subsection 18

6. Optimized Global Speed Profile as a Function of Distance Steps for the Starting Time

7. Comparison of Fuel Maps using Willans Line Model

8. Local Adaption Speed Profile for a Random Chosen Vehicle from the Cohort for the Traveling Time 


\section{LIST OF TABLES}

1. List of Mathematical Symbols Used for Fuel Consumption Minimization 8

2. Global Fuel Consumption and Traveling Time Comparison 20

3. Fuel Consumption and Traveling Time Comparison in Local Adaption 21 


\section{EXECUTIVE SUMMARY}

As reported by the U.S. Energy Information Administration, about $29 \%$ of U.S. energy consumption in 2017 was used for transporting people and goods, with the largest share coming from cars and trucks. Therefore, reducing vehicle energy usage and greenhouse gas emissions has been recognized as a long-time strategic goal by the transportation community.

To take advantage of the benefits of both trajectory optimization and powertrain optimization methods, a group of researchers (Lim et al., 2016) utilized a two-stage hierarchy in designing eco-driving systems. The first stage, operating from the planning aspect, aimed to optimize vehicles' trajectories, with the objective of minimizing total fuel consumption. Then, grounded on the obtained speed profile, the second stage performed real-time adjustment in response to the changes in the driving environment. Despite numerical studies having proven the effectiveness of such a control hierarchy, the first stage of the model used highway speed limit as the baseline for trajectory optimization; hence, it can only be implemented under level of service "A" or "B" when all vehicles can drive at freeflow speed. To overcome this limitation, later studies incorporated traffic prediction into the control loop and utilized the predicted profile of average traffic speed in the near future as the first-stage optimization baseline: see Lim et al. (2017) and Huang et al. (2018). Then, the extended model can be implemented under various congestion levels. In addition, under a CAV environment, Huang et al. (2018) added gear reduction optimization in the powertrain control function and developed a lane-changing decision module for better performance of the eco-driving system.

Following the same two-stage control framework, this study develops a multi-objective model to optimize the trajectory of CAVs on the freeway. The proposed control objectives include travel time minimization, fuel consumption minimization, and traffic safety improvement. The first stage, designed for CAV trajectory planning, is carried out with two optimization submodules. Collecting traffic information via vehicle-to-vehicle (V2V) and vehicle-toinfrastructure (V2I) platforms, the first module functions to predict the freeway traffic states in the near future and accordingly optimize CAVs' speed profile to minimize total freeway travel time. Then, grounded on the obtained speed profile, the second eco-driving model would optimize the aggregated fuel consumption for the whole considered CAV platoon. The second stage, for real-time control purposes, is developed to ensure the operational safety of CAVs. Particularly, real-time adaptation actions would be placed on CAVs to dynamically adjust speeds and make lane-changing decisions in response to local driving conditions.

The main contributions of this work are summarized as follows: (a) accounting for the impact of CAVs' operations on nearby human-driving vehicles (HVs); (b) constructing an optimization framework, at the planning level, that can concurrently reduce freeway travel time and total fuel consumption; and (c) developing platooning functions that can coordinate the operations of multiple CAVs under the proposed eco-driving control platform. The planning aspect takes into account global traffic information for CAV trajectory optimization, while the operational aspect mainly deals with real-time local optimization. 


\section{ECO-DRIVING CONTROL ARCHITECTURE}

\section{LITERATURE REVIEW}

In the literature, many algorithms have been reported in support of the design of vehicular ecodriving systems, and most of them have aimed to control vehicles' speeds and trajectories. Early studies in such domains have mainly focused on the operation of single vehicles and have treated topographical information as the key control input. For example, "eco-cruise control," which dynamically adjusts cruise speed according to roadway grade information, has shown great promise in improving vehicle fuel usage efficiency (Park et al., 2011). This function was later extended to ecological, adaptive cruise control, which further accounts for the impact of nearby vehicles (Wang et al., 2014). Following the same notion but utilizing optimization models, another group of studies devoted efforts to optimizing either vehicles' real-time speeds (Hooker, 1988; Kamal et al., 2011) or their trajectories (Kohut et al., 2009; Nunzio et al., 2013). Notably, those optimization models often take advantage of energy gains on downhill roadway segments to overcome uphill gravity resistances, and this control strategy was further implemented on heavy vehicles. Numerical examples have shown significant savings of truck fuel consumption using this approach (Hellström et al., 2010).

The eco-driving control models on single vehicles, as reviewed above, are effective only under light traffic conditions. With the increase in roadway congestion level, acquiring realtime traffic information becomes essential due to the necessity of accounting for interactions between nearby vehicles. Fortunately, recent technological advancements in network communication and on-line computation enable the implementation of connected automated vehicle (CAV) technology, which greatly enriches the collected real-time traffic information. By exchanging data between vehicles and infrastructure, connected vehicle (CV) applications have demonstrated significant benefits in improving the safety and mobility of transportation as well as reducing emissions (Dey et al. 2016).

Current automated vehicles (AVs) mostly rely on different types of sensors. Ultrasonic, radar, and camera technologies allow AVs to observe and analyze their surroundings and to automatically select suitable driving behaviors, such as acceleration and lane changing (Silva et al., 2017). When connectivity is added into an AV-based system, the vehicle joins the class of connected automated vehicles (CAVs) - vehicles which are equipped with both sensors for detection and on-board units (OBUs) for communications. Specifically, the added V2V technology allows CAVs to exchange critical vehicle status data such as vehicle speed, location, and acceleration, and the V2I platform supports vehicles' communications with infrastructure (Ma et al., 2009).

Since CAV technology brings unparalleled benefits, many researchers have investigated its application in supporting eco-driving control algorithms. Hu et al. (2016) classified existing studies into two categories: vehicle trajectory control and powertrain control. Under various applications such as intelligent merging (Dafflon et al., 2015; Scarinci and Heydecker, 2014), platooning (Wang et al., 2014a; Wang et al., 2014b; Huang et al., 2014), and ecocruise control (Nyitchogna et al., 2014), the first category of research optimized the CAVs' speed profile and acceleration rate, with the objective of minimizing fuel consumption. The second category, focused on a real-time operational environment, aimed to optimize 
key control parameters in CAVs' powertrain system (Girault, 2004; Zulkefli et al., 2014; Wang et al., 2013). Such a control logic has been implemented on regular vehicles, electric vehicles, and hybrid vehicles. Notably, to ensure the effectiveness of the proposed powertrain optimization models in real-time operations, it is crucial to explore efficient solution algorithms or heuristics. Dynamic programming (DP), one of the most commonly used tools, was adopted in a group of studies (Mensing et al., 2011; Luu et al., 2010). However, later studies pointed out that DP may still fall short of efficiency due to the increasing computational complexity. To overcome such limitations, other methodologies, grounded on Model Predictive Control (MPC) and quadratic programming (QP), were developed by researchers: see Jing (2014) and Xu et al. (2014).

In summary, studies in the first category, which aimed to optimize trajectories, are capable of capturing the long-term impacts of CAVs when implementing eco-driving functions. However, those optimization models were developed based on strong assumptions or traffic predictions, which limits their effectiveness in real-time operations. In contrast, powertrain control models can satisfy on-line operation needs by dealing with a relatively short control horizon while generally producing less optimized solutions in the long term.

\section{OVERVIEW OF THE PROPOSED FRAMEWORK}

This study aims to address the challenges of CAV trajectory optimization and control under a mixed CAV and HV environment. As shown in Figure 1, traffic sensors and Roadside Units (RSUs) are the two primary infrastructure components that are installed at roadside. Traffic sensors will be able to collect real-time aggregated traffic data such as five-minute flow and mean speed. RSUs would be responsible for facilitating data exchanges between $\mathrm{CAVs}$ and local computational units through V2I communication channels. To support vehicles' automation function, CAVs are also equipped with on-board sensors such as radars, LiDARs, and cameras. Those sensors would allow CAVs to be aware of their driving environment: more specifically, the locations and speeds of nearby vehicles. In most existing automation functions of AVs, e.g., Tesla, the control logic sets a desired driving speed, and the self-driving module will dynamically adjust the vehicle's speed while maintaining a safe distance from other vehicles. It can be viewed as an extension of Adaptive Cruise Control (ACC) done by adding automated wheel maneuvers in response to roadway changes in horizontal alignment. Some AVs with higher automation levels may also add lane-changing decision-making functions. Hence, with the integration of vehicle connectivity and automation technology, CAVs will be able to acquire enriched real-time information and can support the determination of CAVs' optimal desired speed profile. Following that principle, this study aims to develop a multi-objective eco-driving system that can concurrently minimize CAVs' fuel consumption, reduce freeway travel time, and improve highway safety. Notably, the proposed models would account for the trajectory control of both CAV platoons and individual CAVs. 


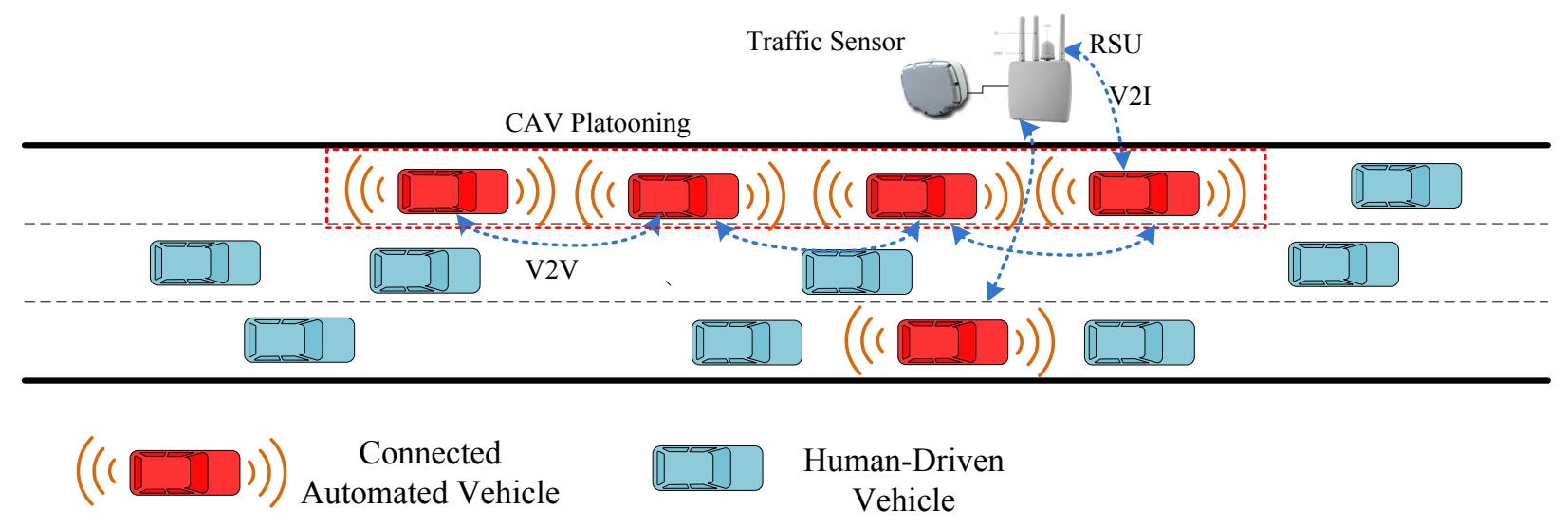

Figure 1. Mixed CAV and HV Driving Environment

Figure 2 shows the system architecture, which includes three key modules: data collection and processing, planning-level optimization, and operational-level real-time control. Using collected traffic flow data and CAV trajectory data, the speed optimization model, embedded into roadside computational units, would determine the desired speed of approaching CAV platoons and individual CAVs with the objective of minimizing total freeway travel time. Notably, the speed optimization would be based on a prediction model that can project freeway traffic state in the next control horizon under the impact of CAV speed changes. Then, according to the obtained speed profile, the eco-driving model would function to produce the optimal trajectories of all detected CAVs with the objective of minimizing CAV fuel consumption. After the completion of optimizations at the planning level, the resulting desired speed profile will be sent to the CAVs, i.e., leaders of platoons and non-platoon CAVs. At the operation level, CAVs would make speed adaptions in response to the real-time driving environment to ensure the minimal safe distance requirement is satisfied. Particularly, real-time operation of CAV platoons would include longitudinal control, e.g., consensus control, sting stability, merging control, and platoon splitting. 


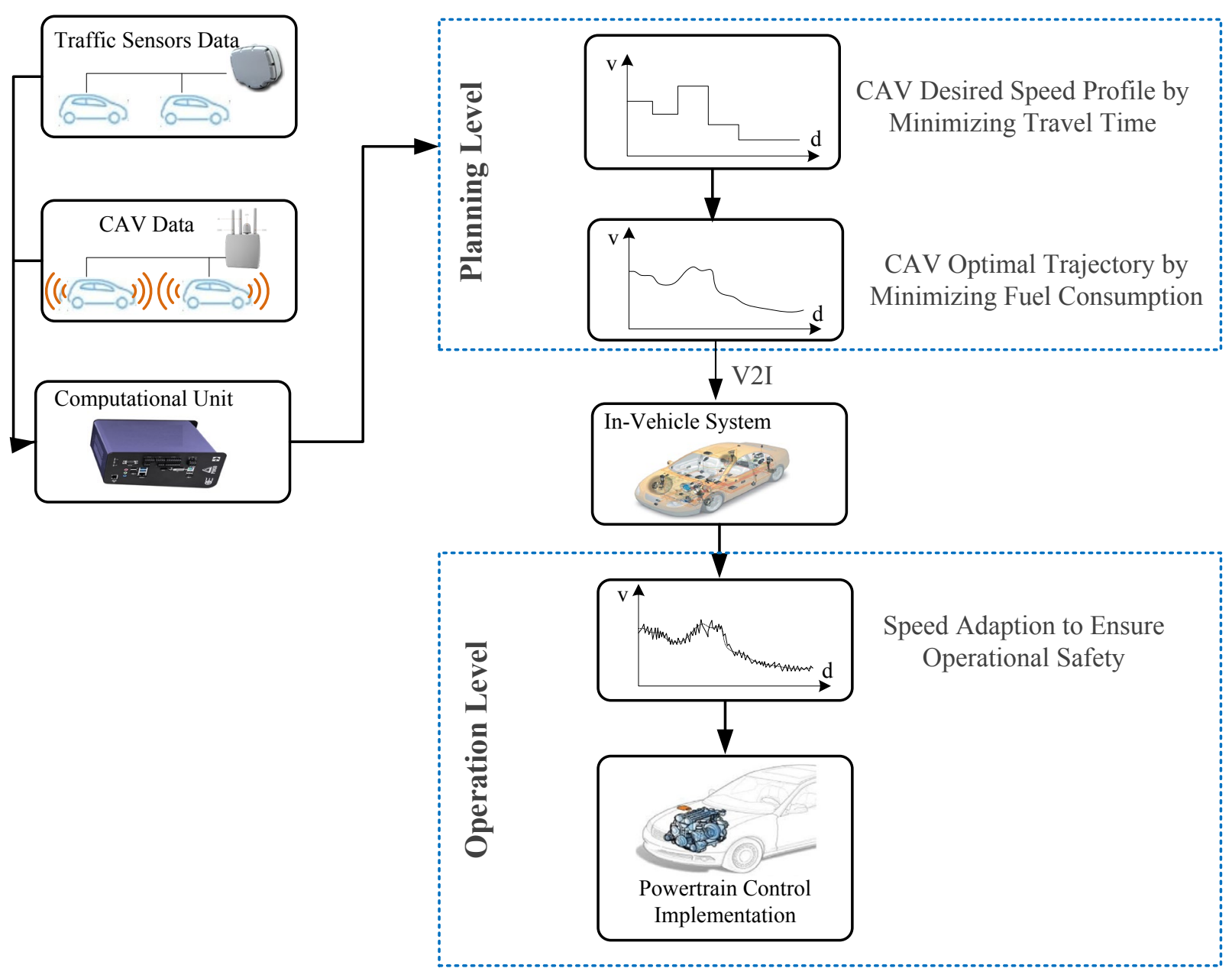

Figure 2. Overview of the Two-Stage Control Framework 


\section{OPTIMIZATION OF CAV TRAJECTORIES AT THE PLANNING LEVEL}

As discussed above, the optimization of CAV trajectories at the planning level include two primary steps: the first step aims to minimize total travel time, and the second step addresses the fuel consumption optimization issue.

\section{TRAVEL TIME MINIMIZATION}

Since an optimized trajectory profile needs to be sent to the CAVs before they leave the V2I communication range, the optimization model at the planning level shall focus on computational efficiency. Hence, this study implements a macroscopic traffic flow model as the baseline for travel time minimization. As shown in Figure 3, the target freeway segment is conceptually divided into $\mathrm{N}$ subsections with a unit length of $\Delta L$. Notably, each subsection can have at most one on-ramp and one off-ramp.

Denoting the density of subsection $j$ during time interval $k$ as $d_{i}(k)$, the control objective of minimizing total freeway travel time over the next control horizon, e.g., 5 min, can be formulated as follows:

$\min \sum \sum \lambda_{i} d_{i}(k) \Delta T$

where $\lambda_{i}$ represents the number of lanes at subsection $i$ and $\Delta T$ the length of each time interval.

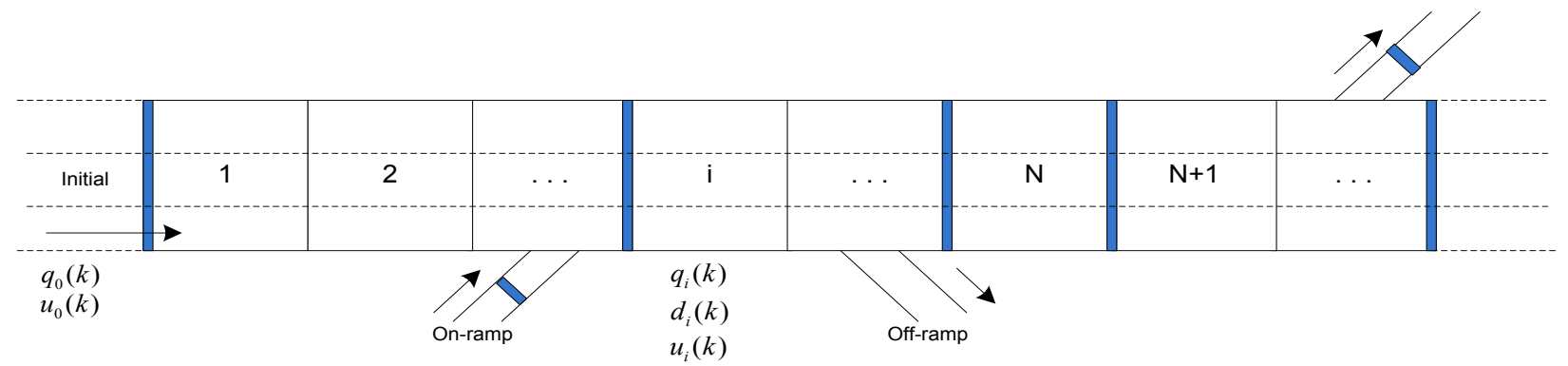

Figure 3. Freeway Segmentations

Also, for safety reasons, the speed variation between consecutive intervals shall be set within the following boundaries:

$-\delta \leq u_{f, j i} v_{i}(k)-u_{f, j i} v_{i}(k-1) \leq \delta$

where $u_{f}$ is the free-flow speed, $v_{i}(k)$ is the desired speed of CAVs, and $\delta$ is the maximal allowed speed variation (e.g., $5 \mathrm{mph}$ ). According to the control logic of AVs' compliance with desired speed, the following constraints shall be satisfied as well:

$u_{j a m} \leq u_{j, i}(k) \leq u_{f, j i} v_{i}(k)$ 
where $u_{j, i}(k)$ is the average speed of CAVs at subsection $j$ during time interval $\mathrm{k}$ and $u_{j a m}$ is the jammed speed.

To support the proposed optimization model, this study implements a macroscopic traffic flow model that can function to predict future traffic state such as speeds, flows, and density, given various desired speed profiles for CAVs. Notably, the conventional traffic flow model, which treats all vehicles as a group in each freeway subsection, may fall short of effectiveness, as trajectory control is placed only to CAVs but not HVs. Meanwhile, the operation of CAVs would affect HVs' speeds since they are sharing the road. To overcome such issues, this study extended the macroscopic model by dividing vehicles into different classes (i.e., CAVs and HVs). The inter-correlations among flow, density, and speed are as follows:

$$
\begin{aligned}
& d_{j, i}(k+1)=d_{j, i}(k)+\frac{\Delta T}{L_{i} \lambda_{i}}\left[q_{j, i, i n}(k)-q_{j, i, o u t}(k)+r_{j, i}(k)-s_{j, i}(k)\right] \\
& q_{1, i, i n}(k)=\left(1-\alpha_{i}\right)\left[q_{1, i-1, \text { out }}(k)+q_{2, i-1, \text { out }}(k)\right] \\
& q_{2, i, i n}(k)=\alpha_{i}\left[q_{1, i-1, \text { out }}(k)+q_{2, i-1, \text { out }}(k)\right] \\
& V_{j, i}\left[d_{j, i}(k)\right]=u_{f, j i} \exp \left[-\frac{1}{a_{j i}}\left(\frac{d_{1, i}(k)+d_{2, i}(k)}{d_{c r, j i}}\right)^{a_{j i}}\right] \\
& u_{1, i}(k+1)=u(k)+\frac{\Delta T}{\tau_{i}}\left[V_{1, i}(k)-u_{1, i}(k)\right]+\frac{\Delta T}{L_{i}} u_{1, i}(k)\left[u_{1, i-1}(k)-u_{1, i}(k)\right]- \\
& \frac{\gamma_{i} \Delta T}{\tau_{i} L_{i}} \frac{\left[d_{1, i+1}(k)+d_{2, i+1}(k)-d_{1, i}(k)-d_{2, i}(k)\right]}{\left[d_{1, i}(k)+d_{2, i}(k)\right]}-\frac{\beta_{i}(\mathrm{k}) \Delta T}{\tau_{i}}\left[V_{1, i}(k)-V_{2, i}(k)\right] \\
& u_{2, i}(k+1)=u_{2, i}(k)+\frac{\Delta T}{\tau_{i}}\left[V_{2, i}(k)-u_{2, i}(k)\right]+\frac{\Delta T}{L_{i}} u_{2, i}(k)\left[u_{2, i-1}(k)-u_{2, i}(k)\right]- \\
& \frac{\gamma_{i} \Delta T}{\tau_{i} L_{i}} \frac{\left[d_{1, i+1}(k)+d_{2, i+1}(k)-d_{1, i}(k)-d_{2, i}(k)\right]}{\left[d_{1, i}(k)+d_{2, i}(k)\right]} \\
& q_{j, i}(k)=\lambda_{i} d_{j, i}(k) u_{j, i}(k)
\end{aligned}
$$

Vehicle class 1 and class 2 represent HVs and CAVs, respectively. To reflect the impact of CAV traiectorv control on HVs' speeds, a term capturing CAV speed impact, $\beta_{i}(\mathrm{k}) \Delta T / \tau_{i}\left[V_{1, i}(k)-V_{2, i}(k)\right]$, is introduced into Equation (8). When HVs are behind CAVs in the traffic stream, a HV may choose either to follow the leading CAV or to change lanes. If a "follow" decision was made, the HV would have a similar speed as CAVs. Hence, the value of the CAV speed impact factor, $\beta_{i}(k)$, shall be subject to traffic demand level and CAV penetration rate. In this study, the initial values of $\beta_{i}(k)$ calibrated by extensive simulation experiments were adopted, see Lu, 2016, and they were updated once the 
real-time information becomes available from traffic sensor data and CAV trajectory data.

Then, the objective function in Equation (1) can be rewritten as:

$\min \sum \sum \lambda_{i}\left[d_{1, i}(k)+d_{2, i}(k)\right] \Delta T$

It shall be noted that the proposed optimization model can be solved very efficiently due to: (a) the implementation of a macroscopic traffic flow model for prediction, and (b) limited feasible region for searching for an optimal solution due to the constraints in Equation (2). Hence, this model can satisfy planning needs in the real-time environment.

\section{FUEL CONSUMPTION MINIMIZATION}

Table 1. List of Mathematical Symbols Used for Fuel Consumption Minimization

\begin{tabular}{|c|c|}
\hline Symbol & Definition \\
\hline$A, B, C, D, X$ & Vehicle speed state equation parameters \\
\hline$A_{d}$ & Frontal area of the vehicle \\
\hline$\beta_{1}, \beta_{2}, \gamma_{1}, \gamma_{2}$ & Fuel rate model parameters \\
\hline$C_{1}, C_{2}, C_{3}$ & Vehicle parameters \\
\hline$C_{d}$ & Drag coefficient \\
\hline$C_{r}$ & Rolling resistance coefficient \\
\hline$\Delta D_{t}$ & Safety distance \\
\hline$F_{\text {brake }}$ & Brake force \\
\hline$f_{r}$ & Final drive ratio \\
\hline$g$ & Gravity \\
\hline$g_{r}$ & Gear ratio \\
\hline
\end{tabular}




\begin{tabular}{|c|c|}
\hline Symbol & Definition \\
\hline$h, l, V_{m}$ & Safety distance model parameters \\
\hline$J$ & Fuel consumption \\
\hline$m$ & Vehicle mass \\
\hline$\dot{m}_{f}(t)$ & Instantaneous mass fuel rate \\
\hline$N_{f r}$ & Efficiency of the final drive \\
\hline$N_{g r}$ & Efficiency of gear box/torque converter \\
\hline$n_{r}$ & Gear number \\
\hline$\rho$ & Air density \\
\hline$r_{w}$ & Wheel radius \\
\hline$\Delta s$ & Distance of each segment \\
\hline$S$ & Total traveling distance \\
\hline$T_{e}$ & Engine torque \\
\hline$\theta$ & Road grade \\
\hline$t$ & Traveling time \\
\hline$u$ & Instantaneous powertrain control parameter vector \\
\hline$U$ & Global powertrain control parameter vector \\
\hline
\end{tabular}

Once the total travel time is optimized as shown in Section 3.1, it is possible to readily use the resulting traffic speed profile to promote fuel consumption minimization. Table I shows a list of mathematical symbols used for fuel consumption minimization. The processing of non-platoon CAVs can be found in Huang et al. (2018), where trajectory optimization was 
performed in each CAV individually For each platooning CAV with a given travel distance of length $S$, the distance $S S$ is partitioned into $n n$ segments. The optimized traffic speed profile is expressed as $\hat{V}(s, t)=\left[\hat{V}\left(s_{1}, t\right), \ldots, \hat{V}\left(s_{n}, t\right)\right]$, where $\hat{V}\left(s_{i}, t\right)$ denotes the optimized speed profile in the $i^{\text {th }}$ segment at time $t t$. Then, this optimized, baseline speed profile will serve as a guide when minimizing the aggregated fuel consumption in a cohort of $M$ vehicles traveling though the distance of length $S$ :

$$
I_{\text {tot }}=\sum_{m=1}^{M} J_{m}
$$

where $J_{\text {tot }}$ denotes the total aggregated fuel consumption of a cohort of $M M$ vehicles on the considered path for a given time period denoted by $\left[t_{0}, t_{f}\right]$, and $I_{m}$ indicates the total fuel consumption of the $m^{\text {th }}$ vehicle in the cohort, which can be expressed as:

$$
I_{m}=\int_{t_{0}}^{t_{f}} \dot{m}_{f, m}(t) d t
$$

where $\dot{m}_{f, m}(t)$ denotes instantaneous mass fuel rate $(\mathrm{kg} / \mathrm{s})$ of the $m^{\text {th }}$ vehicle. To express $\dot{m}_{f, m}(t)$, the Willans line approximation is adopted:

$$
\dot{m}_{f, m}=f\left(T_{e, m} \mid \omega_{m}\right)= \begin{cases}k_{1}\left(\omega_{m}\right) T_{e, m}+c_{1}\left(\omega_{m}\right) & \text { for } T_{e, m} \geq 0 \\ k_{2}\left(\omega_{m}\right) T_{e, m}+c_{2}\left(\omega_{m}\right) & \text { for } T_{e, m}<0\end{cases}
$$

where $k_{i}\left(\omega_{m}\right)$ and $c_{i}\left(\omega_{m}\right)$ are linear functions of the engine rotational speed of the $m^{\text {th }}$ vehicle $\omega_{m}$, and $T_{e, m}$ denotes the engine torque of the $m^{\text {th }}$ vehicle. Thus, the fuel rate $\dot{m}_{f, m}$ can further be expressed as:

$$
\dot{m}_{f, m}=f\left(T_{e, m}, \omega_{m}\right)=\left(\beta_{1} \omega_{m}+\beta_{2}\right) T_{e, m}+\gamma_{1} \omega_{m}+\gamma_{2}
$$

Engine rotation speed $\omega_{m}$ can be further expressed as a function of vehicle velocity and wheel radius:

$$
\omega_{m}(t)=f_{r} g_{r}\left(n_{r}\right) \cdot \frac{v_{m}(t)}{r_{w}}
$$

where $v_{m}(t)$ denotes vehicle instantaneous velocity $(\mathrm{m} / \mathrm{s}), r_{w}$ denotes wheel radius, $f_{r}$ is the final drive ratio, and $g_{r}\left(n_{r}\right)$ is the gear ratio given a gear number $n_{r}$. Constant gear box efficiency is assumed for fixed gear number. Thus, the gear number $n_{r}$ is assumed to be controlled solely by the vehicle velocity $v_{m}$ and the direction of the acceleration. The gear ratio can be further expressed as a function of velocity 


$$
g_{r}\left(n_{r}\right)=g_{r}\left(f_{s}\left(v_{m}\right)\right)
$$

where $f_{s}$ is the function that determines gear number from current velocity: $n_{r}=f_{s}\left(v_{m}\right)$. Since a distance-based approach is used to express total fuel consumption in this work, $J_{m}$ can be rewritten as:

$$
I_{m}=\sum_{k=0}^{n-1} \dot{m}_{f, m}(k) \Delta t_{k}
$$

where $n$ is the total number of equally divided distance steps for a total traveling distance of $S$, and $\Delta t_{k}$ is the time needed to travel the $k^{\text {th }}$ distance step, which can be further expressed as a function of step distance $\Delta s=S / n$ and average velocity at $k^{\text {th }}$ distance step $v_{m}(k): \Delta t_{k} \approx \Delta s / v_{m}(k)$. By combining Eqs. (12)-(18), total fuel consumption for the $m^{\text {th }}$ vehicle traveling through the distance $S$ can be expressed as:

$$
I_{m}=\sum_{k=0}^{n-1}\left(\left(\beta_{1} f_{r} g_{r}\left(f_{s}(v)\right) \frac{v_{m}(k)}{r_{w}}+\beta_{2}\right) T_{e, m}(k)+\gamma_{1} f_{r} g_{r}\left(f_{s}\left(v_{m}\right)\right) \frac{v_{m}(k)}{r_{w}}+\gamma_{2}\right) \frac{\Delta s}{v_{m}(k)} .
$$

By neglecting the effect of some of the non-critical terms such as $\gamma_{1} \gamma_{1}$ and $\gamma_{2} \gamma_{2}$, Equation (8) can be simplified to:

$$
I_{m}=\sum_{k=0}^{n-1}\left(\beta_{1} f_{r} \frac{g_{r}\left(f_{s}\left(v_{m}\right)\right)}{r_{w}} T_{e, m}(k) \Delta s\right)
$$

Then the state equation for the speed at k-th distance step can be expressed as:

$$
v_{m}(k)^{2}=\left(1-\frac{2 C_{2} \Delta s}{m a}\right) v_{m}(k-1)^{2}+\left[\frac{2 C_{1} \Delta s}{m a},-\frac{2 \Delta s}{m a}\right]\left[\begin{array}{c}
T_{e, m}(k-1) \\
F_{\text {brake,m }}(k-1)
\end{array}\right]-\frac{2 C_{3} \Delta s}{m a}
$$

where $m a$ denotes the mass of the vehicle $(\mathrm{kg}), F_{\text {brake, } m}$ denotes the brake force applied at one distance step, and $C_{1}, C_{2}$, and $C_{3}$ are vehicle parameters defined as:

$$
\begin{aligned}
& C_{1}=\frac{f_{r} g_{r}\left(f_{s}\left(v_{m}\right)\right) N_{f r} N_{g r}\left(n_{r}\right)}{r_{w}} \\
& C_{2}=\frac{1}{2} \rho C_{d} A_{d} \\
& C_{3}=m a \cdot g \cdot C_{r} \cos \theta(t)+m a \cdot g \cdot C_{r} \sin \theta(t)
\end{aligned}
$$

where $N_{f r}$ denotes the efficiency of the final drive, $N_{g r}\left(n_{r}\right)$ denotes the efficiency of a 
bear box and a torque converter, $\rho$ denotes the air density $\left(\mathrm{kg} / \mathrm{m}^{3}\right), C_{d}$ denotes the drag coefficient, $A_{d}$ denotes the frontal area of the vehicle $\left(\mathrm{m}^{2}\right), g$ is the gravity $\left(\mathrm{m} / \mathrm{s}^{2}\right), C_{r}$ is the rolling resistance coefficient, and $\theta(t)$ is the road gradient (rad). For a given vehicle and a fixed road, and assuming that the initial velocity at time $t=0$ is $v_{m}(0)$, then according to the Equation (21), the velocity at the $k^{\text {th }}$ distance step can be expressed as a function of the initial velocity $v_{m}(0)$, the engine torque $T_{e, m}$, and the brake force $F_{\text {brake, } m}$ :

$$
v_{m}(k)=f_{v}\left(v_{m}(0), T_{e, m}(i), F_{\text {brake }, m}(i)\right), \quad i=0, \ldots, k-1
$$

Fuel consumption for the entire driving distance $S$ is performed in the space of the powertrain control vector given the initial vehicle velocity. As mentioned before, also taken into account is the estimated average traffic speed profile during optimization. In order to consider velocity profile as an optimization constraint, it is necessary to express velocity as a function of the optimization parameter vector U. Rewriting Equation (21) yields:

$$
X(k+1)=A(k) X(k)+B(k) u(k)-D(k)
$$

where the terms are defined as follows:

$$
\begin{aligned}
& X(k)=v(k)^{2}, \\
& A(k)=1-\frac{2 C_{2} \Delta s}{m a}, \\
& B(k)=\left[\frac{2 C_{1} \Delta s}{m a},-\frac{2 \Delta s}{m a}\right], \\
& u(k)=\left[T_{e}(k), F_{\text {brake }}(k)\right]^{T}, \text { and } \\
& D(k)=\frac{2 C_{3} \Delta s}{m a} .
\end{aligned}
$$

Then, the vehicle's longitudinal states for all distance steps can be expressed in matrix form: 


$$
\begin{aligned}
& X=\left[\begin{array}{c}
X(0) \\
X(1) \\
\vdots \\
X(n-2) \\
X(n-1)
\end{array}\right]=\left[\begin{array}{c}
1 \\
A(0) \\
\vdots \\
A(n-3) \cdots A(0) \\
A(n-2) \cdots A(0)
\end{array}\right] X(0)
\end{aligned}
$$

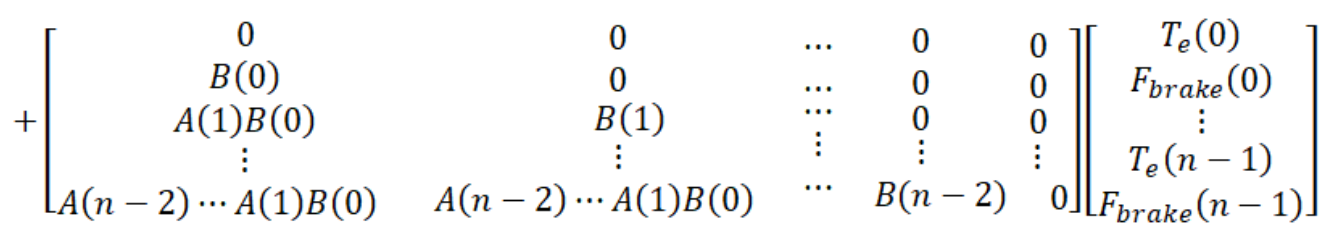

$$
\begin{aligned}
& +\left[\begin{array}{ccccc}
0 & 0 & \cdots & 0 & 0 \\
1 & 0 & \cdots & 0 & 0 \\
\vdots & \vdots & \vdots & \vdots & \vdots \\
A(n-3) \cdots A(1) & A(n-2) \cdots A(1) & \cdots & 0 & 0 \\
A(n-2) \cdots A(1) & A(n-2) \cdots A(2) & \cdots & 1 & 0
\end{array}\right]\left[\begin{array}{c}
-D(0) \\
-D(1) \\
\vdots \\
-D(n-2) \\
-D(n-1)
\end{array}\right]
\end{aligned}
$$

Equation (25) can be rewritten using matrices $\bar{A}, \bar{B}, U, C$, and $D$ :

$$
X=\bar{A} X(0)+\bar{B} U+\bar{C} D
$$

Equation (26) can be further manipulated:

$$
\bar{B} U=X-\bar{A} X(0)-\bar{C} D
$$

As can be seen from Equation (27), the powertrain control parameter vector $U$ is expressed as a linear function of $X$. Thus, it is possible to impose linear equalities to the global fuel consumption optimization process. In order to impose a realistic speed profile, the optimization constraints are therefore applied such that the resulting speed profile is between the interval $\left[V_{\min }(s, t), V_{\max }(s, t)\right]$, where $V_{\min }(s, t)$ denotes the minimum allowed speed deducted from estimated average traffic speed $\hat{V}(s, t) \hat{V}(s, t)$, and $V_{\max }(s, t)$ is determined by the maximum speed deducted from estimated average traffic speed $\hat{V}_{\max }(s, t)$ and safety driving distance:

$$
V_{\max }(s, t)=\min \left(\hat{V}_{\max }(s, t), V_{D}(s, t)\right)
$$

where $\hat{V}_{\text {max }}(s, t)$ is the maximum speed deducted from estimated average traffic $\hat{V}(s, t)$, and $V_{D}(s, t)$ is the maximum allowed speed to ensure a safe distance from the preceding vehicle:

$$
V_{D}(s, t)=(\Delta D(t)-l) / h
$$


where $\Delta D(t)$ is the distance between the actual vehicle and the preceding vehicle, and $l$ and $h$ are constant values which are set to 2 . Note that in the case where $V_{D}(s, t)<V_{\min }(s, t)$, the safety distance constraint will override $V_{\min }(s, t)$, which results in updated speed constraint $\left[0, V_{D}(s, t)\right]$. Based on the above discussion, the global fuel consumption optimization can be formulated as follows:

$$
\begin{gathered}
\min \sum_{m=1}^{M} \sum_{k=0}^{n-1} \beta_{1} f_{r} \frac{g_{r}\left(f_{s}(v)\right)}{r_{w}} T_{e, m}(k) \Delta s \\
0 \leq U \leq U_{\max }
\end{gathered}
$$

subject to

$$
\left[\begin{array}{c}
-\bar{B} \\
\bar{B}
\end{array}\right] U \leq\left[\begin{array}{c}
-\left(X_{\min }-\bar{A} X(0)-\bar{C} D\right) \\
X_{\max }-\bar{A} X(0)-\bar{C} D
\end{array}\right]
$$

where $U_{\max }$ denotes the upper boundary of the powertrain control parameter $\left(U_{\max }=\left[T_{\max , m(0)}, F_{\max , m(0)}, \ldots, T_{\max , m(n-1)}, F_{\max , m(n-1)}\right] m=1, \ldots, M, X_{\min }\right)$ and $X_{\max }$ are traffic speed boundaries: $X_{\min }=V_{\min }^{2}(s, t), X_{\max }=V_{\max }^{2}(s, t)$. The global optimization formulated in Equation (18) provides optimal powertrain control that minimizes the aggregated fuel consumption for a cohort of $M$ vehicles for a given driving distance $S$ by taking into account road condition and global traffic speed profile. Note that global traffic speed profile is estimated dynamically and can be updated periodically to reflect global traffic flow change. In such cases, global optimization formulated in Equation (30) is also performed periodically using rolling horizon control logic to ensure updated global optimal powertrain control.

In this work, genetic algorithm (GA) is used for long-term global optimization. Developed based on the notion of biological evolution, GA aims at solving both constrained and unconstrained optimization problems by iteratively modifying a population of individual solutions. Individuals are selected randomly at each generation from the current population to be parents, who will then generate children for the next generation. The population gradually evolves towards an optimal solution. Lower and upper bounds and linear constraints shown in Equation (30) are taken into account at each iteration in the optimization process. Mutation and crossover functions are used to produce new individuals at every generation, and only feasible new points are generated with respect to the linear and bound constraints. Due to the small scale of the problem, experimental tests showed that all computational work can be completed within a few seconds.

Once the optimal powertrain control parameters $U_{\text {opt }}$ are obtained, one can easily reconstruct the corresponding speed profile for each vehicle:

$$
V_{\text {opt }}=\sqrt{\bar{A} X(0)+\bar{B} U_{o p t}+\bar{C} D}
$$




\section{REAL-TIME CAV TRAJECTORY CONTROL AT OPERATION LEVEL}

\section{SPEED ADAPTION OF CAVS}

Even though optimal trajectories (speed profiles) are produced at the planning level, the operation of CAVs in real-time still needs a speed adaption function that can account for the impacts of unpredictable traffic perturbations. For example, the leader of a CAV platoon or a non-platoon CAV may experience a slowdown of the preceding vehicle. Hence, to guarantee a safe driving environment, the speed adaption function will effectively make adjustment of CAVs' speeds and ensure safe distance between vehicles.

Notably, the speed adaption activity is repeatedly performed at a relatively small time step $\Delta t$ (e.g., 1 second). At each time step $i$, on-board sensors and in-vehicle data processing systems can be used to obtain the distance between the CAV and its preceding vehicle, denoted by $d_{i}(t)$, as well as the speed of the CAV and its preceding vehicle, denoted by $u_{i}(t)$ and $u_{i-1}(t)$. Examples of on-board sensors are Radar, LiDAR, Camera, and so on. When $d_{j}(t)$ is less than a safe distance $\Delta \mathrm{D}$, the speed adaption function will be activated. Particularly, $\Delta \mathrm{D}$ can be computed as follows, according to Lim et al. (2016):

$$
\Delta D=h * u_{i}(t)+l
$$

where $h$ and I are model parameters and both can be set to be 2. For non-platoon CAVs, vehicles' speed will be smoothly reduced:

$$
\begin{aligned}
& u_{i}(t)=u(t-1)-a_{i}(t) \Delta t \\
& a_{i}(t)=\frac{u_{i}(t)^{2}-u_{i-1}(t)^{2}}{a\left[\Delta D-\int_{t_{0}}^{t} u_{i}(t) d t-d_{\min }\right]}
\end{aligned}
$$

where $a_{i}(t)$ denotes to the deceleration rate at time $t, t_{0}$ denotes the time when the speed adaption is activated, and $d_{\min }$ denotes the minimal safe distance between a CAV and a $\mathrm{HV}$ in the traffic stream.

For a CAV platoon, speed adaption on the platoon leader will inevitably affect all other following CAVs. Hence, to concurrently account for the safety constraint and fuel consumption saving needs, this study performs an operation-level optimization by neglecting constant terms and terms with small variations in the planning level model. Also, to satisfy the real-time operational need, the objective function can be expressed in the following quadratic programming form: 


$$
\min _{U(i)} w_{2} u(i)^{T} B(i)^{T} u(i)+\left[w_{1} K-2 w_{2} B(i) V_{o p t, i+1}^{2}\right] u(i)
$$

subject to

$$
0 \leq u(i) \leq u_{i, \max } 0 \leq u(i) \leq u_{i, \max }
$$

$$
B(i) u(i) \leq v_{\max }-A(i) X(i)+D(i)
$$

where $u(i)$ is the speed vector of CAV platoon with leader $i, u_{i, \max }$ is the upper boundary for $u(i)$, and $v_{\max }$ denotes the maximum speed allowed at time $i+1$ to ensure a safe driving distance. This optimization model has the form standard to quadratic programming, which can be efficiently solved by existing algorithms such as the interior point method. However, the optimization may fail in applications under several circumstances. For example, an HV from the neighboring lanes suddenly changes lanes to move to the front of CAV platoon, or the preceding HV reduces its speed harshly. In such cases, safety would be the only concern, and all CAVs would be forced to brake.

\section{CAV PLATOON OPERATIONS}

Similar to Cooperative Adaptive Cruise Control (CACC), the operation of CAV platoons may include the following: (a) merge a non-platoon CAV into the platoon; (b) platoon CAV leaves the platoon; (c) combine two or more platoons into one; (d) split a platoon into two or more platoons; and (e) maintain the stability of platoons. Since extensive research efforts have been devoted to such domains, the proposed system can directly implement existing control algorithms. 


\section{NUMERICAL EXAMPLES}

A VISSIM simulation was used for performance evaluations of the proposed models, per Yang et al. (2020). Recognizing that a simulation model cannot accurately reflect reality until it is well-calibrated, the team collected field data for calibration. Then, the VISSIMCOM interface was used to develop a program to execute the local adaption function using VB.NET; the MYSQL database was used to simulate the on-line operational procedure. The real-time traffic information is detected and the target vehicle's trajectory is adjusted during the simulation. The road condition and vehicle parameters used in the study are the following:

$$
\begin{aligned}
& S=6500 \mathrm{~m}, \Delta s=25 \mathrm{~m}, n=260, T_{\max }=220 \mathrm{Nm}, F_{\max }=3120 \mathrm{~N}, F_{r}=8, N_{f r}=0.9, \\
& r_{w}=0.25 \mathrm{~m}, m=3000 \mathrm{~kg}, g=\frac{9.8 m}{\mathrm{~s}^{2}}, C_{r}=0.01, \rho=1.225, C_{d}=0.3, A_{d}=0.5 \mathrm{~m}^{2}, \\
& \theta(t)=0
\end{aligned}
$$

The simulated freeway segment is $6 \mathrm{~km}$ in length and is divided into 12 subsections. Inflow pattern from the most upstream subsection is shown in Figure 4.

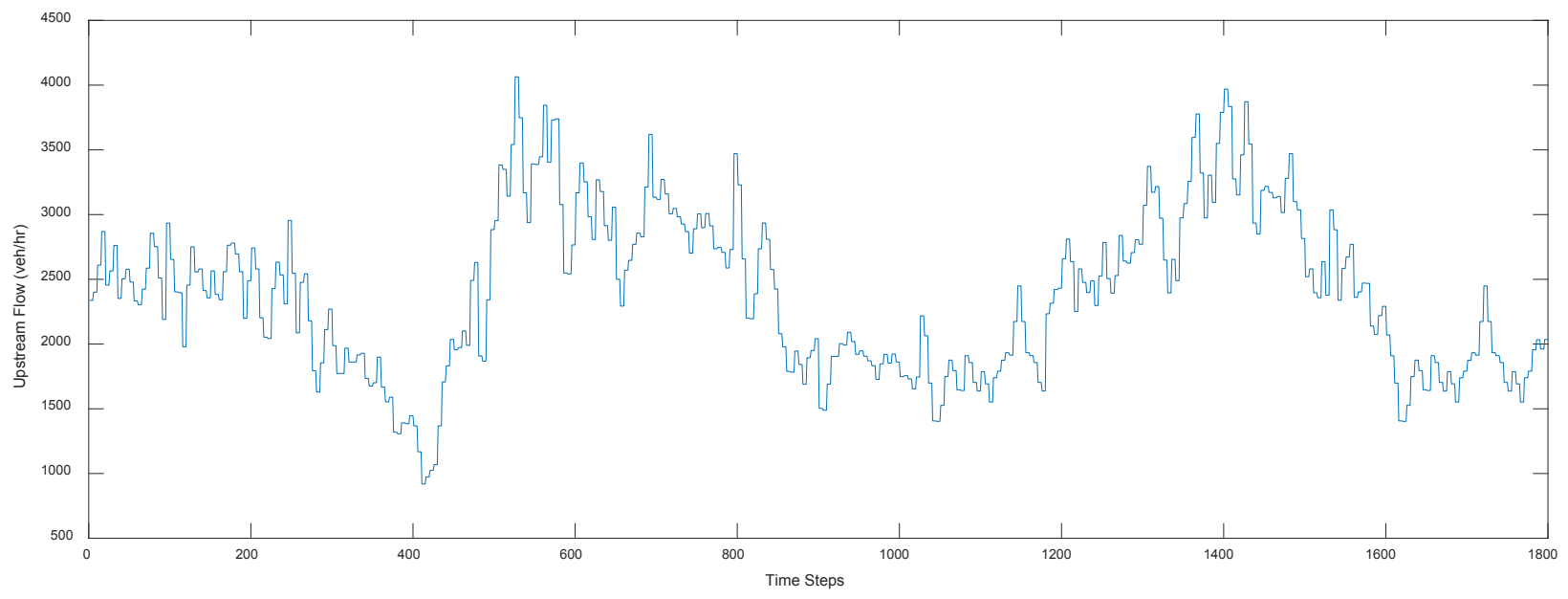

Figure 4. Upstream Inflow to the Study Site

\section{CAV TRAJECTORY OPTIMIZATION RESULTS (PLANNING LEVEL)}

For system performance evaluation, without loss of generality, the network was simulated for a period of 5 hours and CAV penetration rate set as $15 \%$. As the first control objective is to minimize total freeway travel time, Figure 5 shows the time-dependent average speed distribution on the most congested subsection (i.e., subsection 8). By comparison with the case without CAV trajectory control, one can observe that the proposed control framework can greatly increase the average traffic speed on the freeway. Further investigation into total travel time shows a reduction of $18 \%$ over the 5 -hour control period. 


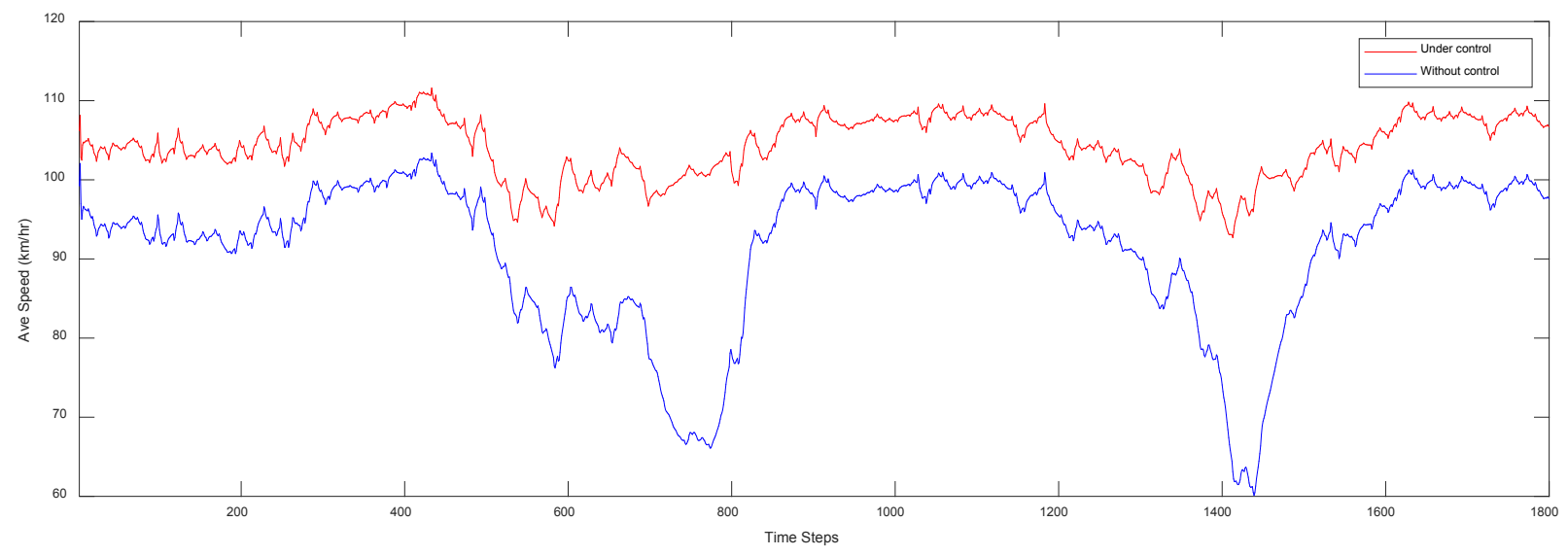

Figure 5. Time-Dependent Average Speed Distribution on the Most Congested Subsection

Given the speed profile produced by the travel time minimization model, the next step is to generate optimal CAV trajectories with fuel consumption minimization. For convenience of discussion on CAV platoon operations, this numerical experimental test particularly investigate 10-CAV platoons that entered the study site at one, two, three, and four hours, respectively.

Figure 6 also shows the optimized speed profile of the selected ten vehicles at one, two, three, and four hours. The speed profile is plotted with respect to distance steps for a total number of $n=260$ steps at each optimization time considered. The speed boundary constraints are plotted in green curves, and speed profiles of different vehicles are plotted in different colors in Figure 6 . It can be observed that the pattern of average traffic speed profile for the entire 6500-meter trajectory of 260 distance steps remains very similar for the four different considered times, despite the time spread of four hours. The average traffic started with a rather high speed of approximately $30 \mathrm{~m} / \mathrm{s}$, then it went down to approximately $20 \mathrm{~m} / \mathrm{s}$ in the middle of the trajectory, and it slowly increased at the end of the trajectory. As can be observed in Figure 6 , the platoon of vehicles considered generally follows a similar speed profile for the entire trajectory, which shows the consistency in the global optimization process.

To further illustrate the fuel consumption savings provided by the proposed approach, the second column of Table 2 shows the average fuel consumption, travel time, and average speed of the considered cohort of ten vehicles during the trajectory using the proposed Willans line vehicle model. The values shown in Table 2 are averaged from the four travel times considered. The third column in Table 2 shows the optimized long-term fuel consumption and travel time obtained using a more accurate vehicle model based on a fuel map generated from Autonomie. Figure 7 shows a combined fuel map generated using the Willans line model (dashed curve) and Autonomie (solid curve), as shown in Lim et al. (2016). It can be observed that the Willans line model curve closely follows the curve generated from Autonomie. The accuracy of the Willans line model can be further confirmed by observing the second and third column in Table 2: the fuel consumption and travel time values obtained using the Willans line model are aligned with the values 
obtained from the fuel map generated from Autonomie. The fourth column of Table 2 shows the average fuel consumption of other vehicles on the same trajectory without the longterm optimization. It can be observed that the cohort of ten vehicles with the proposed long-term optimization approach had significantly less fuel consumption, with an average of $0.34 \mathrm{~kg}$ as compared to $0.37 \mathrm{~kg}$ from other vehicles on the same trajectory without optimization. Also, the proposed approach resulted in a slightly higher average speed of $24.5 \mathrm{~m} / \mathrm{s}$.
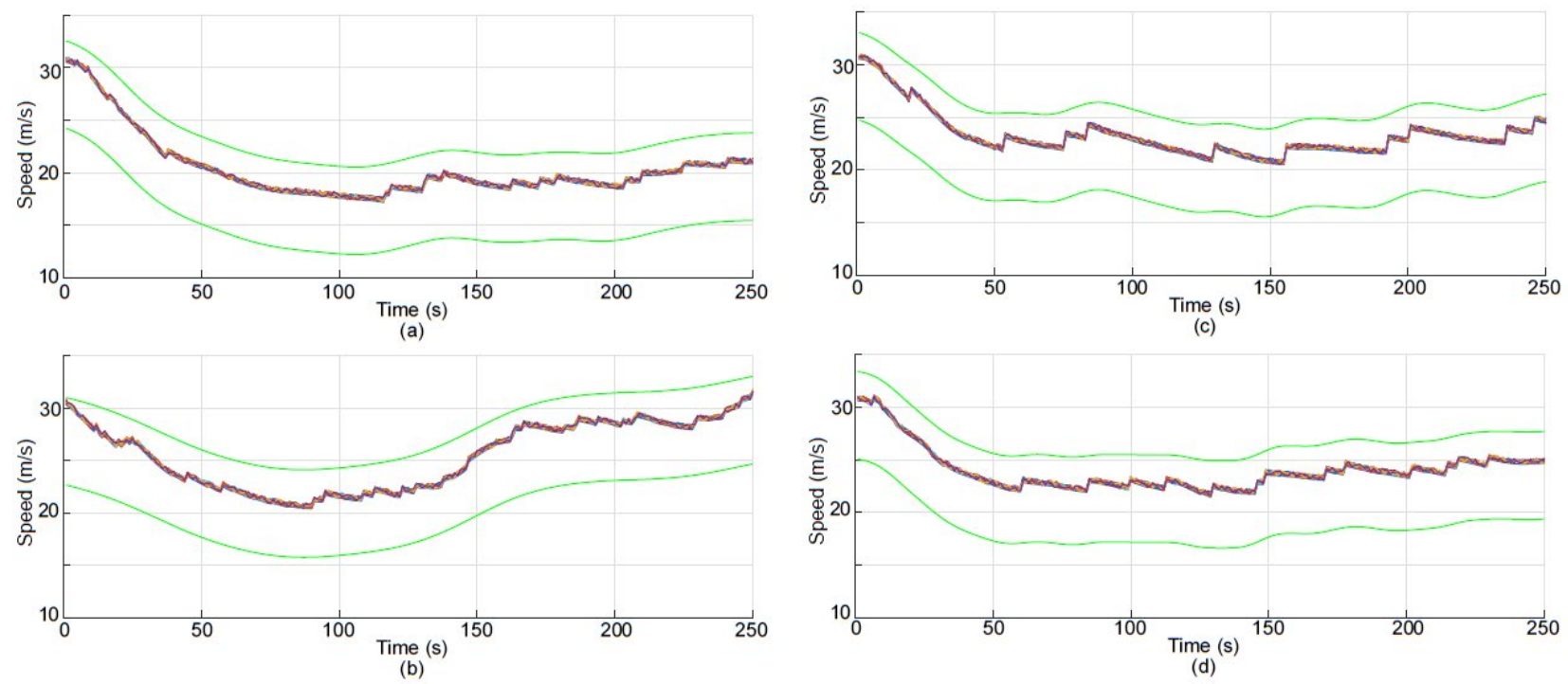

Figure 6. Optimized Global Speed Profile as a Function of Distance Steps for the Starting Time (a) $1 \mathrm{~h}$, (b) $2 \mathrm{~h}$, (c) $3 \mathrm{~h}$, (d) $4 \mathrm{~h}$

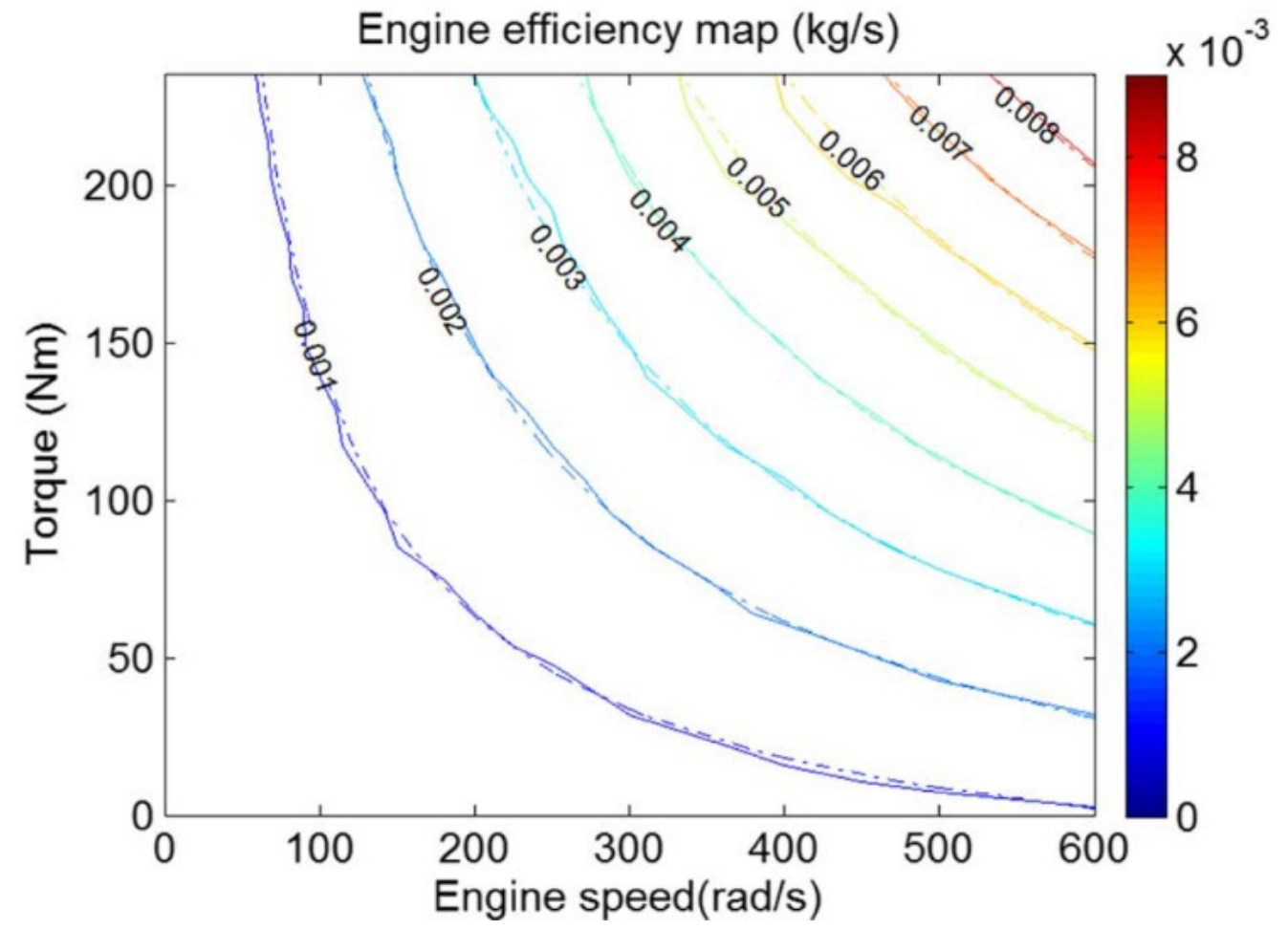

Figure 7. Comparison of Fuel Maps Using Willans Line Model (ashed curve) and Autonomie (solid curve) 
Table 2. Global Fuel Consumption and Traveling Time Comparison

\begin{tabular}{lccc}
\hline & $\begin{array}{c}\text { Proposed (Willans } \\
\text { line model) }\end{array}$ & $\begin{array}{c}\text { Proposed (Fuel map } \\
\text { from Autonomie) }\end{array}$ & Average Traffic \\
\hline Fuel Consumption $(\mathrm{kg})$ & 0.34 & 0.34 & 0.37 \\
Traveling Time $(\mathrm{s})$ & 266 & 266 & 271.5 \\
Average Speed $(\mathrm{m} / \mathrm{s})$ & 24.5 & 24.5 & 23.9 \\
\hline
\end{tabular}

\section{REAL-TIME CAV TRAJECTORY CONTROL RESULTS (OPERATION LEVEL)}

Once the optimized long-term optimization was performed for the cohort of vehicles with safety distance considerations included in the optimization, the local adaption for real-time CAV trajectory control was then performed to adapt to local random perturbations. To mimic other vehicles' random lane changes on the same trajectory, at every time step, a lane change probability of 0.01 was inserted for vehicles from other lanes changing to the current lane. This random change from other vehicles resulted in abrupt speed reductions due to local safety distance maintaining operations, as can be observed in Figure 8. For illustration purposes, the speed profile is shown for one vehicle from the cohort in local adaptation for each of the traffic observation times. The blue curves in Figure 8 show the local adapted speed profile, and the red curves show the optimized global speed profile obtained from the long-term optimization process. As can be observed in Figure 8, the abrupt speed reductions occurred in order to force the implementation of a safe distance, and then local adaptation quickly modified the speed to match the global optimal speed profile, which ensures minimum fuel consumption while maintaining a safe driving distance.
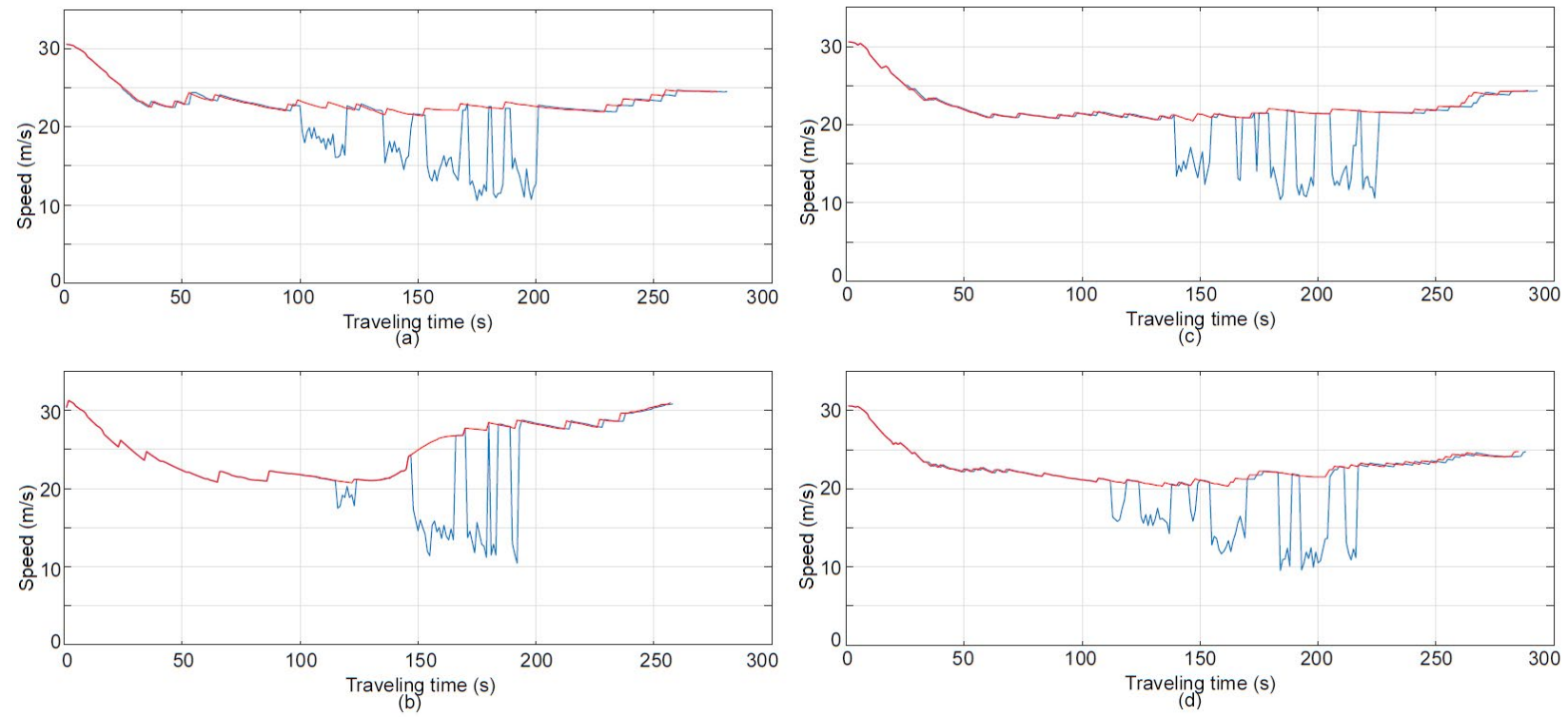

Figure 8. Local Adaption Speed Profile for a Random Chosen Vehicle from the Cohort for the Traveling Time (a) $1 \mathrm{~h}$, (b) $2 \mathrm{~h}$, (c) $3 \mathrm{~h}$, (d) $4 \mathrm{~h}$ 
Table 3. Fuel Consumption and Traveling Time Comparison in Local Adaption

\begin{tabular}{|c|c|c|c|}
\hline & $\begin{array}{c}\text { Proposed (Willans line } \\
\text { model) }\end{array}$ & $\begin{array}{l}\text { Proposed (Fuel map } \\
\text { from Autonomie) }\end{array}$ & Average Traffic \\
\hline Fuel Consumption (kg) & 0.38 & 0.38 & 0.42 \\
\hline Traveling Time (s) & 271 & 271 & 278.3 \\
\hline Average Speed $(\mathrm{m} / \mathrm{s})$ & 23.9 & 23.9 & 23.4 \\
\hline
\end{tabular}

Table 3 shows the updated fuel consumption and traveling time in the local adaptation stage. It can be observed that the fuel consumption obtained from local adaptation is slightly higher than that obtained from the optimized global speed profile, due to the abrupt speed reductions discussed before. The fourth column in Table 3 shows the average results from other vehicles on the same trajectory without local optimization. It can be observed that this approach still provides lesser fuel consumption at the local adaptation stage as compared to other vehicles on the same trajectory.

This project has presented a multi-objective control framework to design eco-driving algorithms for platooning CAVs, which leverages the advances of both connectivity and vehicle automation technologies. Following a two-stage control logic, the first stage, at the planning level, aimed at producing optimal trajectories of CAVs that can concurrently reduce freeway total travel time and CAV fuel consumption. Particularly, those models adopt realtime data, including traffic sensor data and CAV trajectory information, as input. Grounded on a macroscopic traffic flow model, the first optimization model yielded the profile of CAVs' desired speed, with the objective of minimizing total freeway travel time. Then, the second optimization functioned to generate optimal CAV trajectories in compliance with the obtained speed profile, with the goal of reducing fuel consumption. Notably, the algorithm can address the needs of both CAV platoons and non-platoon CAVs. The second stage, for real-time control purposes, was developed to ensure the operational safety of CAVs. Particularly, real-time adaptation actions were placed on CAVs to dynamically adjust speeds in response to local driving conditions. Based on extensive numerical simulations, the results have confirmed the effectiveness of the proposed framework in both mitigating freeway congestion and reducing vehicles' fuel consumption. 


\section{ABBREVIATIONS AND ACRONYMS}

\begin{tabular}{ll}
\hline ACC & Adaptive Cruise Control \\
AVs & Automated Vehicles \\
CACC & Cooperative Adaptive Cruise Control \\
CV & Connected Vehicle \\
CAV & Connected Automated Vehicle \\
DSRC & Dedicated Short Range Communications \\
DP & Dynamic Programming \\
GA & Genetic Algorithm \\
HVs & Human-Driving Vehicles \\
MPC & Model Predictive Control \\
OBUs & On-Board Units \\
QP & Quadratic Programming \\
RSU & Roadside Unit \\
V2I & Vehicle-to-Infrastructure \\
V2V & Vehicle-to-Vehicle \\
\hline
\end{tabular}




\section{BIBLIOGRAPHY}

Barić, D., Zovak, G., \& Periša, M. "Effects of Eco-Drive Education on the Reduction of Fuel Consumption and CO2 Emissions." Promet - Traffic - Traffico 25, no. 3 (2013): 265-272.

Dafflon, B., Vilca, J., Gechter, F., \& Adouane, L. "Adaptive Autonomous Navigation using Reactive Multi-Agent System for Control Law Merging." Procedia Computer Science 51 (2015): 423-432.

De Nunzio, G., De Wit, C. C., Moulin, P., \& Di Domenico, D. "Eco-Driving in Urban Traffic Networks using Traffic Signals Information." International Journal of Robust and Nonlinear Control 26, no. 6 (2016): 1307-1324.

Desjardins, C., \& Chaib-Draa, B. "Cooperative Adaptive Cruise Control: A Reinforcement Learning Approach." IEEE Transactions on Intelligent Transportation Systems 12, no. 4 (2011): 1248-1260.

Dey, Kakan Chandra, et al. "Vehicle-to-Vehicle (V2V) and Vehicle-to-Infrastructure (V2I) Communication in a Heterogeneous Wireless Network: Performance Evaluation." Transportation Research Part C: Emerging Technologies 68 (2016): 168-184.

Eben Li, S., Li, K., \& Wang, J. "Economy-Oriented Vehicle Adaptive Cruise Control with Coordinating Multiple Objectives Function." Vehicle System Dynamics 51, no. 1 (2013): 1-17.

Enomoto, K., Fujiki, Y., \& Takemoto, H. (2011). U.S. Patent Application No. 13/121,480.

Girault, A. "A Hybrid Controller for Autonomous Vehicles Driving on Automated Highways." Transportation Research Part C: Emerging Technologies 12, no. 6 (2004): 421-452.

Hao, P., Wang, Z., Wu, G., Boriboonsomsin, K., \& Barth, M. J. Intra-platoon vehicle sequence optimization for eco-cooperative adaptive cruise control. In Proceedings of IEEE 20th International Conference on Intelligent Transportation Systems, October 2017.

Hellström, E., Åslund, J., \& Nielsen, L. "Design of an Efficient Algorithm for Fuel-Optimal Look-Ahead Control." Control Engineering Practice 18, no. 11 (2010): 1318-1327.

Hooker, J. N. "Optimal Driving for Single-Vehicle Fuel Economy." Transportation Research Part A: General 22, no. 3 (1988): 183-201.

Hu, J., Shao, Y., Sun, Z., Wang, M., Bared, J., \& Huang, P. "Integrated Optimal EcoDriving on Rolling Terrain for Hybrid Electric Vehicle with Vehicle-Infrastructure Communication." Transportation Research Part C: Emerging Technologies 68 (2016): 228-244. 
Huang, K., Yang, X., Lu, Y., Mi, C. C., \& Kondlapudi, P. "Ecological Driving System for Connected/Automated Vehicles Using a Two-Stage Control Hierarchy." IEEE Transactions on Intelligent Transportation Systems 19, no. 7 (2018): 2373-2384.

Huang, Z., Wu, Q., Ma, J., \& Tian, W. Modeling and simulation of cooperative strategies for vehicle platoon longitudinal control. In CICTP 2014: Safe, Smart, and Sustainable Multimodal Transportation Systems, 2014 (pp. 498-512).

Jiang, D., Taliwal, V., Meier, A., Holfelder, W., \& Herrtwich, R. "Design of 5.9 GHz DSRCBased Vehicular Safety Communication." IEEE Wireless Communications 13, no. 5 (2006).

Jing, J. (2014). Vehicle Fuel Consumption Optimization using Model Predictive Control Based on V2V Communication. Ph.D. dissertation, The Ohio State University.

Kamal, M. A. S., Mukai, M., Murata, J., \& Kawabe, T. "Ecological Vehicle Control on Roads with Up-Down Slopes." IEEE Transactions on Intelligent Transportation Systems 12, no. 3 (2011): 783-794.

Kenney, J. B. Dedicated Short-Range Communications (DSRC) Standards in the United States. Proceedings of the IEEE 99, no. 7 (2011): 1162-1182.

Kohut, N., Hedrick, K., \& Borrelli, F. Integrating Traffic Data and Model Predictive Control to Improve Fuel Economy. In 12th IFAC Symposium on Control in Transportation Systems, 2009 (pp. 155-160).

Lim, H., Su, W., \& Mi, C. C. "Distance-Based Ecological Driving Scheme using a TwoStage Hierarchy for Long-Term Optimization and Short-Term Adaptation." IEEE Transactions on Vehicular Technology 66, no. 3 (2017): 1940-1949.

Lu, C. Y. (2016). Integrated Variable Speed Limit and Ramp Metering Control for Managing Recurrent Freeway Congestion. Ph.D. Dissertation, University of Maryland.

Luu, H. T., Nouveliere, L., \& Mammar, S. Ecological and Safe Driving Assistance System: Design and Strategy. In 2010 IEEE Intelligent Vehicles Symposium (IV), June 2010 (pp. 129-134).

Ma, X., Chen, X., \& Refai, H. H. "Performance and Reliability of DSRC Vehicular Safety Communication: A Formal Analysis." EURASIP Journal on Wireless Communications and Networking 2009, no. 1 (2009): 969164.

Mensing, F., Trigui, R., \& Bideaux, E. Vehicle Trajectory Optimization for Application in ECO-driving. In 2011 IEEE Vehicle Power and Propulsion Conference, 2011 (pp. $1-6)$.

Nyitchogna, P. L. B., Nouvelière, L., Orfila, O., Glaser, S., \& Mammar, S. Impact of 
Full Speed Range ACC on the Traffic, the Safety and the Energy Consumption. In Proc. Transport Research Arena 5th Conference: Transport Solutions from Research to Deployment, April 2014 (pp. 1-10).

Park, S., Rakha, H., Ahn, K., \& Moran, K. Predictive eco-cruise control: Algorithm and potential benefits. In 2011 IEEE Forum on Integrated and Sustainable Transportation System (FISTS), pp. 394-399.

Sakhdari, B., \& Azad, N. L. "A Distributed Reference Governor Approach to Ecological Cooperative Adaptive Cruise Control." IEEE Transactions on Intelligent Transportation Systems 19, no. 5 (2018): 1496-1507.

Sahlholm, P., \& Johansson, K. H. Segmented Road Grade Estimation for Fuel Efficient Heavy Duty Vehicles. In 49th IEEE Conference on Decision and Control (CDC), Atlanta, GA, 2010 (pp. 1045-1050).

Scarinci, R., \& Heydecker, B. "Control Concepts for Facilitating Motorway On-Ramp Merging Using Intelligent Vehicles.” Transport Reviews 34, no. 6 (2014): 775-797.

Silva, C. M., Masini, B. M., Ferrari, G., \& Thibault, I. A Survey on Infrastructure-Based Vehicular Networks. Mobile Information Systems, 2017.

Taliwal, V., Jiang, D., Mangold, H., Chen, C., \& Sengupta, R. Empirical determination of channel characteristics for DSRC vehicle-to-vehicle communication. In Proceedings of the 1st ACM International Workshop on Vehicular Ad Hoc Networks, October 2004, pp. 88.

U.S. Energy Information Administration (2018), "Different types of energy sources are used for transportation in the United States," https://www.eia.gov/ energyexplained/?page=us_energy_transportation (accessed July 6, 2018).

Wang, M., Daamen, W., Hoogendoorn, S. P., \& van Arem, B. "Rolling Horizon Control Framework for Driver Assistance Systems. Part I: Mathematical Formulation and Non-Cooperative Systems." Transportation Research Part C: Emerging Technologies 40 (2014a): 271-289.

Wang, M., Daamen, W., Hoogendoorn, S. P., \& van Arem, B. "Rolling Horizon Control Framework for Driver Assistance Systems. Part II: Cooperative Sensing and Cooperative Control." Transportation Research Part C: Emerging Technologies 40 (2014b): 290-311.

Wang, M., Daamen, W., Hoogendoorn, S., \& van Arem, B. "Potential Impacts of Ecological Adaptive Cruise Control Systems on Traffic and Environment." IET Intelligent Transport Systems 8, no. 2 (2014): 77-86.

Wang, Y., Zhang, H., \& Sun, Z. "Optimal Control of the Transient Emissions and the Fuel Efficiency of a Diesel Hybrid Electric Vehicle." Proceedings of the Institution of 
Mechanical Engineers, Part D: Journal of Automobile Engineering 227, no. 11 (2013): 1546-1561.

Wang, Z., Kulik, L., \& Ramamohanarao, K. Proactive Traffic Merging Strategies for Sensor-Enabled Cars. In Automotive Informatics and Communicative Systems: Principles in Vehicular Networks and Data Exchange, 2009 (pp. 180-199). IGI Global.

Wang, Z., Wu, G., Hao, P., Boriboonsomsin, K., \& Barth, M. Developing a PlatoonWide Eco-Cooperative Adaptive Cruise Control (CACC) System. In 2017 IEEE Intelligent Vehicles Symposium June 2017 (pp. 1256-1261).

Xu, Q., Mak, T., Ko, J., \& Sengupta, R. Vehicle-to-Vehicle Safety Messaging in DSRC. In Proceedings of the 1st ACM International Workshop on Vehicular Ad Hoc Networks, October 2004 (pp. 19-28).

Xu, S., Deng, K., Li, S. E., Li, S., \& Cheng, B. Legendre Pseudospectral Computation of Optimal Speed Profiles for Vehicle Eco-Driving System. In 2014 IEEE Intelligent Vehicles Symposium Proceedings, June 2014 (pp. 1103-1108).

Yang, X., Huang, K., Zhang, Z., Zhang Z.A., \& Lin, F. Eco-Driving System for Connected Automated Vehicles: Multi-Objective Trajectory Optimization. IEEE Transactions on Intelligent Transportation Systems (accepted).

Yin, J., ElBatt, T., Yeung, G., Ryu, B., Habermas, S., Krishnan, H., \& Talty, T. Performance Evaluation of Safety Applications over DSRC Vehicular Ad Hoc Networks. In Proceedings of the 1st ACM International Workshop on Vehicular Ad Hoc Networks, October 2004 (pp. 1-9).

Zulkefli, M. A. M., Zheng, J., Sun, Z., \& Liu, H. X. "Hybrid Powertrain Optimization with Trajectory Prediction Based on Inter-Vehicle-Communication and Vehicle-Infrastructure-Integration." Transportation Research Part C: Emerging Technologies 45 (2014): 41-63. 


\section{ABOUT THE AUTHORS}

\section{KE HUANG}

Dr. Huang received the B.S., M.S., and Ph.D. degrees in Electrical Engineering from the Université Grenoble Alpes, Grenoble, France, in 2006, 2008, and 2011, respectively. He was a Postdoctoral Research Associate at the University of Texas at Dallas, Richardson, TX, USA, from 2012 to 2014. In 2014, he joined the Department of Electrical and Computer Engineering at San Diego State University, San Diego, CA, USA, where he is now an Associate Professor. His research focuses on intelligent vehicles, very-large-scale integration (VLSI) testing and security, and computer-aided design of integrated circuits (ICs).

He has published over 30 journal and conference papers and served as a Program Committee Member in various IEEE conferences, as well as a Guest Editor of Springer Journal of Electronic Testing Theory and Applications (JETTA). He was awarded a Ph.D. Fellowship from the French Ministry of National Education from 2008 to 2011. He was a recipient of the Best Paper Award from the 2015 IEEE VLSI Test Symposium (VTS'15), and he also received the Best Paper Award from the 2013 Design Automation and Test in Europe (DATE'13) conference.

\section{XIANFENG TERRY YANG}

Dr. Yang received the B.S. degree in civil engineering from Tsinghua University, Beijing, China in 2009; he received the M.S. and Ph.D. degrees in civil engineering from the University of Maryland (College Park) in 2012 and 2015, respectively.

Dr. Yang is currently an Assistant Professor in the Department of Civil \& Environmental Engineering at the University of Utah. Before joining the University of Utah, he had been working as an Assistant Professor at San Diego State University. His current research areas include machine learning application in transportation, evacuation planning and operation, traffic operations with connected automated vehicles, intelligent transportation systems, traffic safety, and network flow modeling. 


\section{PEER REVIEW}

San Jose State University, of the California State University system, and the Mineta Transportation Institute (MTI) Board of Trustees have agreed upon a peer review process required for all research published by MTI. The purpose of the review process is to ensure that the results presented are based upon a professionally acceptable research protocol. 


\section{MTI BOARD OF TRUSTEES}

Founder, Honorable

Norman Mineta*

Secretary (ret.),

US Department of Transportation

\section{Chair,}

Abbas Mohaddes

President \& $\mathrm{COO}$

Econolite Group Inc.

\section{Vice Chair,}

\section{Will Kempton}

Executive Director

Sacramento Transportation Authority

\section{Executive Director,}

Karen Philbrick, PhD*

Mineta Transportation Institute

San José State University

\section{Winsome Bowen}

Chief Regional Transportation

Strategy

Facebook

\section{David Castagnetti}

\section{Co-Founder}

Mehlman Castagnetti

Rosen \& Thomas

\section{Maria Cino}

Vice President

America \& U.S. Government

Relations Hewlett-Packard Enterprise

\author{
Grace Crunican** \\ Owner \\ Crunican LLC
}

\section{Donna DeMartino \\ Managing Director \\ Los Angeles-San Diego-San Luis \\ Obispo Rail Corridor Agency}

\section{Nuria Fernandez**}

General Manager \& CEO

Santa Clara Valley

Transportation Authority (VTA)

\section{John Flaherty}

Senior Fellow

Silicon Valley American

Leadership Form

\section{William Flynn * \\ President \& CEO \\ Amtrak}

\section{Rose Guilbault}

Board Member

Peninsula Corridor

Joint Powers Board

Ian Jefferies*

President \& CEO

Association of American Railroads
Diane Woodend Jones

Principal \& Chair of Board

Lea + Elliott, Inc.

David S. Kim*

Secretary

California State Transportation

Agency (CALSTA)

\section{Therese McMillan}

Executive Director

Metropolitan Transportation

Commission (MTC)

\section{Bradley Mims}

President \& CEO

Conference of Minority

Transportation Officials (COMTO)

Jeff Morales

Managing Principal

InfraStrategies, LLC

Dan Moshavi, PhD*

Dean, Lucas College and

Graduate School of Business

San José State University

Toks Omishakin*

Director

California Department of

Transportation (Caltrans)
Takayoshi Oshima

Chairman \& CEO

Allied Telesis, Inc.

Paul Skoutelas*

President \& CEO

American Public Transportation

Association (APTA)

Beverley Swaim-Staley

President

Union Station Redevelopment

Corporation

Jim Tymon*

Executive Director

American Association of

State Highway and Transportation

Officials (AASHTO)

\section{Larry Willis*}

President

Transportation Trades

Dept.,AFL-CIO

$*$ = Ex-Officio

$* *=$ Past Chair, Board of Trustees

\section{Directors}

\section{Karen Philbrick, PhD}

Executive Director

\section{Hilary Nixon, PhD}

Deputy Executive Director

\section{Asha Weinstein Agrawal, PhD}

\section{Education Director}

National Transportation Finance

Center Director

\section{Brian Michael Jenkins}

National Transportation Security

Center Director

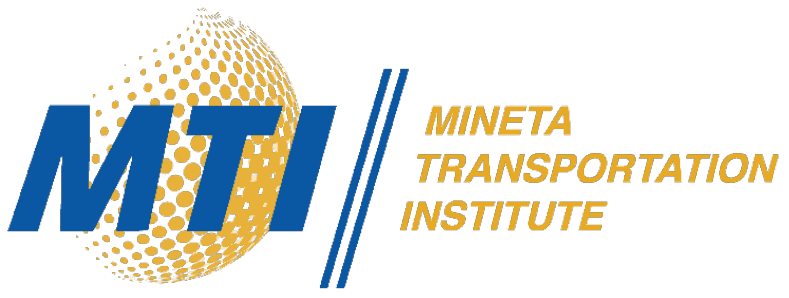

